\title{
Use of Modified Alvarado Score in Diagnosis of Acute Appendicitis: A Prospective Study
}

\author{
Rajendra Jain ${ }^{1}$, Archana M. Kamble², Rachit S. Mitra ${ }^{3}$

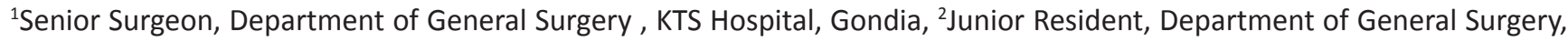 \\ Government Medical College, Nagpur, ${ }^{3}$ Intern, Department of General Surgery, Indira Gandhi Government Medical College, \\ Nagpur, Maharashtra, India.
}

Corresponding author: Dr. Rachit S. Mitra, Intern, Department of General Surgery, Indira Gandhi Government Medical College, Nagpur, Maharashtra, India

DOI: 10.21276/ijcmsr.2018.3.3.29

How to cite this article: Rajendra Jain, Archana M. Kamble, Rachit S. Mitra. Use of modified alvarado score in diagnosis of acute appendicitis: a prospective study. International Journal of Contemporary Medicine Surgery and Radiology. 2018;3(3):C131-C135.

\section{A B S T R A C T}

Introduction: Acute appendicitis is one of the common causes of acute abdomen. The diagnosis of acute appendicitis is usually made on the basis of clinical features and confirmed by ultrasound examination and occasionally by Computerized tomography. This study was conducted to study the importance and diagnostic efficacy of Alvarado score in acute appendicitis and its effect on reducing negative appendectomies.

Material and Methods: We conducted this prospective study comprising of 150 cases who were ill enough to warrant surgery for suspected appendicitis admitted to our institute scoring system described by Alvarado was adopted to reduce negative appendectomy. Patients were included in this study on the basis of a predefined inclusion and exclusion criteria Patients were either operated or managed conservatively on the basis of a combination of Alvarado score and clinical grounds. Surgery was done under general or spinal anesthesia. Data analysis was carried out using Minitab 17 version software.

Results: Out of the 150 studied cases there were 90 (60\%) males and 60 (40\%) females with a M: F ratio of 1:0.66. Most common age group was found to be in between $21-30 \mathrm{yrs}$. Abdominal pain was predominant complaint which was present in all patients $(100 \%)$ followed by anorexia ( $86 \%)$, nausea $(84 \%)$ and constipation (16\%). Most common site of pain was right iliac fossa (100\%) and tenderness in RIF was present in 147 (98\%) patients. Leukocytosis was seen in 85\% cases. Modified Alvarado score was less than 5, 5-6 and more than 6 in 3, 21 and 126 patients respectively.

Conclusion: The Modified Alvarado score is a useful diagnostic tool at a cut-off point of 7 for all patient groups. Modified Alvarado score (7 or more) has a high sensitivity and positive predictive value for the diagnosis of appendicitis and hence can be routinely used in all district general hospitals with basic lab facilities and particularly where facilities of USG Scan or CT scan are not available.

Keywords: Acute Appendicitis, Modified Alvarado Score, Sensitivity, Specificity, Positive Predictive Value

\section{INTRODUCTION}

Acute appendicitis is the acute inflammation of appendix. It is common, sometimes confusing and often treacherous cause of acute abdomen at all age groups. ${ }^{1}$ It is relatively rare in infants, becomes increasingly common in children and early adults, reaching peak in teen and early 20 s. $^{2}$ Of all the abdominal emergencies, acute appendicitis heads the list of causes classified under acute abdomen. It is one of the common causes of surgery consultation associated with quite an amount of morbidity and preventable mortality. ${ }^{3}$ The etiology of acute appendicitis is varied among which obstruction to lumen and infection play an important role. Of all the infections bacteriodes fragilis and E. coli are found to be the most common organism which is responsible for acute appendicitis. ${ }^{4}$
The diagnosis of appendicitis can be difficult, occasionally taxing the diagnostic skills of seven the most experienced surgeon. Likewise the judgmental decisions in the management of patients which appendicular inflammation or abscess can be difficult. The patient with appendicitis first recognizes that he has an episode of pain that is unique and then present to the physician who recognizes the condition. Delays in diagnosis arises from errors on the part of either the patient or physician, and all delays complicate the illness. ${ }^{5}$ The menace of acute appendicitis lies in the frequency with which the peritoneal cavity is infected from this focus, either by perforation or by transmigration of bacteria through appendicular wall. The classic triad of a history compatible with acute appendicitis, pain at the Mc Burney's point and the leukocytosis has diagnostic accuracy rate of less than 80 percent and even when radiological techniques such as 
ultrasonography, computed tomography or radionuclide scanning are included, the accuracy does not usually reach 90 percent. ${ }^{6}$ Patient presenting with acute lower abdominal pain remain a diagnostic challenge. Acute appendicitis is the most common indication for surgery in these patients. After careful clinical evaluation and observations, surgical intervention is undertaken. There is large geographical variation in incidence of appendicitis and the prevalence of diseases that mimic it. Migrating pain, involuntary guarding and persistence or progression of clinical signs are the main criteria favoring the option of surgical intervention. ${ }^{7}$

Despite an increased use of ultrasonography, computerized tomographic scanning and laparoscopy, the rate of misdiagnosis of appendicitis has remained constant (15.3\%), as has the rate of appendicular rupture. ${ }^{8}$ The negative appendectomy rate for women of reproductive age group is $23.2 \%$ with the highest rates identified in women age 40 to 49. The highest negative appendectomy rate is reported for women older than 80 years of age. The possibility of negative appendectomy needs to be carefully weighed against the risk of morbidity and mortality associated with appendicular perforation which is associated serious complications such as, Peritonitis, intra-abdominal abscess formation and septicemia. If immediate interventions are not done the condition may rapidly prove fatal. ${ }^{9}$

When clinical and imaging findings are ambiguous Alvarado scoring system may be used to reduce the negative appendectomy rate without increasing morbidity and mortality. Alvarado put forward a scoring system for diagnosing acute appendicitis. ${ }^{10}$ The scoring system as described by Alvarado was based on 3 symptoms, three signs and two lab findings. According to the scoring system, patients with score of 1-4 were not considered likely to have acute appendicitis. Those patients with a score of 5-6 were considered to have a possible diagnosis of appendicitis but not convincing enough to warrant immediate surgery and those were marked for further review. Those with a score of 7-8 were considered to have a probable acute appendicitis and those with a score of 9-10 were considered to have an almost definite appendicitis and submitted to surgery. The score can increase or decrease on reassessment. The lab findings of leukocytosis was defined as a white cell count in excess of $11,000 / \mathrm{mm} 3$. The Alvarado score was modified by M. Kalan, D. Talbat, W.J. Cunliffe and A.J. Righ. ${ }^{11}$ The Modified Alvarado score excludes, the left shift of neutrophil maturation (\% of segmented immature neutrophils with normal total WBC count). This laboratory parameter was excluded as it was not available on a routine basis in the laboratories. The patient were therefore scored out of 9 rather than 10 points. We conducted this study to find out the diagnostic efficacy and importance of Modified Alvarado score in diagnosis of acute appendicitis and its efficacy in decreasing negative appendectomies.

\section{MATERIAL AND METHODS}

This was a prospective study of 150 patients who were ill enough to warrant surgery for suspected appendicitis admitted to our institute under various surgical units over a period of 1 year. The patients were included in this study on the basis of predefined inclusion and exclusion criteria. Informed consent was taken from all the patients willing to participate in the study. All necessary investigations were done in all patients. The cases subjected to emergency surgery were adequately prepared. Whenever vomiting persisted, Ryles tube aspiration was done. Parenteral fluids, electrolyte supplementation, broad spectrum antibiotic were administered. Hourly temperature, pulse and respiratory chart were maintained.

In order to achieve accuracy in early diagnosis of acute appendicitis modified Alvarado score was used to reduce negative appendectomy rate without increasing mortality and morbidity. The scoring system was initially introduced as an adjunct to diagnosis in order to correct a high false positive appendectomy rate. ${ }^{10}$ In present study we used modified version of Alvarado score by Kalan et $\mathrm{al}^{11}$ in which by excluding one laboratory finding (shift to the left of neutrophil maturation) as this is not available on a routine basis and therefore patients were scored out of 9 rather than 10 points. Depending upon individual presentation of signs and symptoms a score was calculated for each case of suspected acute appendicitis from 9 values. The observed value in each case was added and expressed as end score.

Surgery was done under general or spinal anesthesia. When the diagnosis of acute appendicitis was certain grid-iron incision was employed. Right paramedian incision was used when the diagnosis was doughtful or when frank peritonitis was suspected. Before resection the appendix was assessed. The specimen of appendix was sent for histopathological examination and the reports analysed. A study of observation was done and an attempt was made to correlate the clinical presentations in each patient with the pathological findings.

\section{STATISTICAL ANALYSIS}

The Microsoft office was used to make charts and graphs. Sensitivity, specificity and positive predictive value were determined. The data was tabulated and analysed using statistical software Minitab 17.

\section{RESULTS}

In this Prospective study of 150 patients, the patients who presented with acute symptoms and preoperatively diagnosed to have acute appendicitis were studied on the basis of a predefined inclusion and exclusion criteria. Out of 150 cases there were 90 males and 60 females with a ratio of 1.5:1.

The most common age group of the affected patients was found to be between 21-30 years followed by 11-20 years and 31-40 years. Only 5 patients belonged to the age group of more than 60 years (figure-1).

The analysis of the patients on the basis of presenting symptoms chowed that most common symptom was pain in abdomen which was present in all patients (100\%). The other common symptoms seen were anorexia (86\%) and nausea (84\%).The most common site of pain was right iliac fossa (100\%). In addition to right iliac fossa pain was also present in in between umbilicus and right iliac fossa (70\%) and in epigastric region (70\%). Diffuse pain and central abdominal pain was present in $16 \%$ and $6 \%$ respectively. Majority of the patients presented within 24 hours after the onset of pain, 


\begin{tabular}{|c|c|c|}
\hline Symptoms & Score & \\
\hline Migratory RIF Pain & 01 & \multirow{7}{*}{$\begin{array}{l}\text {-Those patients with scores of }>7-9 \text { underwent an appendectomy. } \\
\text {-Those patients with scores of 5-7, who were thought on clinical grounds to require appendec- } \\
\text { tomy, were operated accordingly. } \\
\text {-Those patients with score of }<5 \text { were observed and managed conservatively and reassessed. } \\
\text {-Those patients who had mass in RIF, were observed and managed conservatively. }\end{array}$} \\
\hline Anorexia & 01 & \\
\hline Nausea/vomiting & 01 & \\
\hline Tenderness in RIF & 02 & \\
\hline Rebound tenderness RIF & 01 & \\
\hline Elevated temperature & 01 & \\
\hline Leucocytosis & 02 & \\
\hline Total & 09 & \\
\hline
\end{tabular}

\begin{tabular}{|l|l|c|c|}
\hline & & No. of patients & Percentage \\
\hline \multirow{5}{*}{ Symptoms } & Pain in Abdomen & 150 & $100 \%$ \\
\cline { 2 - 4 } & Anorexia & 129 & $86 \%$ \\
\cline { 2 - 4 } & Nausea & 126 & $84 \%$ \\
\cline { 2 - 4 } & Constipation & 24 & $16 \%$ \\
\cline { 2 - 4 } & Diarrhea & 9 & $6 \%$ \\
\cline { 2 - 4 } & Burning Micturition & 15 & $10 \%$ \\
\hline \multirow{5}{*}{ Signs } & Tenderness at right iliac fossa & 147 & $98 \%$ \\
\cline { 2 - 4 } & Fever & 128 & $85.33 \%$ \\
\cline { 2 - 4 } & Rebound tenderness & 126 & $22 \%$ \\
\cline { 2 - 4 } & Rovsing's sign & 33 & $3 \%$ \\
\cline { 2 - 4 } & Hyperesthesia at sherren's tringle & 4 & 0 \\
\cline { 2 - 4 } & Mass in RIF & 0 \\
\hline
\end{tabular}

\begin{tabular}{|l|c|c|c|c|c|c|c|c|}
\hline & $\begin{array}{c}\text { No of } \\
\text { Patients }\end{array}$ & $\begin{array}{c}\text { Score } \\
>\mathbf{7 - 9}\end{array}$ & Appendicitis & $\begin{array}{c}\text { Normal } \\
\text { Appendix }\end{array}$ & $\begin{array}{c}\text { Other } \\
\text { Diseases }\end{array}$ & Sensitivity & Specificity & Positive predictive value \\
\hline Male & 75 & 62 & 60 & 1 & 1 & $84.50 \%$ & $50 \%$ & $96.77 \%$ \\
\hline Female & 60 & 52 & 50 & 1 & 1 & $89.28 \%$ & $33.33 \%$ & $96.15 \%$ \\
\hline Children & 15 & 12 & 11 & 1 & 0 & $84.61 \%$ & $0 \%$ & $91.66 \%$ \\
\hline \multicolumn{7}{|c|}{ Table-3: Sensitivity, specificity and positive predictive value of Modified Alvarado Score } \\
\hline
\end{tabular}

\begin{tabular}{|l|c|c|c|c|c|}
\hline & No of Patients & Score $>\mathbf{5 - 6}$ & Appendicitis & Normal Appendix & Other Diseases \\
\hline Male & 75 & 12 & 11 & 1 & 0 \\
\hline Female & 60 & 07 & 6 & 1 & 0 \\
\hline Children & 15 & 02 & 2 & 0 & 0 \\
\hline \multicolumn{7}{|r|}{ Table-4: Modified Alvarado Score (5-6) } \\
\hline
\end{tabular}

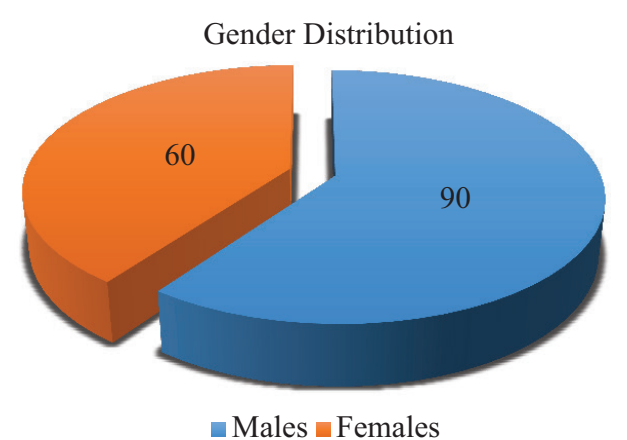

Figure-1: Gender Distribution Of the Studied cases.

most of them presenting with 12-24 hours after onset of pain. On clinical Examination tenderness in right iliac fossa was the most common sign seen in these patients (98\%) followed by rebound tenderness (84\%). Rovsing sign was positive in 33 (22\%) patients (figure-2).

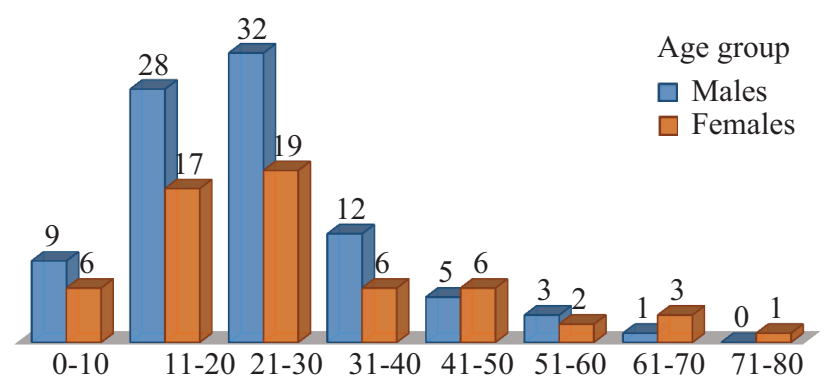

Figure-2: Age groups (in years) of the studied cases.

The analysis of investigations such as total leucocyte count, urine analysis and erect Xray abdomen was done. Out of studied cases 88 (58.67\%) patients had total leucocyte count between 10000-14000 whereas 36 (24\%) patients had TLC between 14000-18000. Remaining 26 (17.33\%patients had a Leucocyte count less than 10000 . The urine microscopic 
examination in our series showed pyuria in $6 \%$ cases and hematuria in 3\% cases. Erect X-Ray abdomen showed abnormalities in 4 patients in the form of ground glass appearance (1.33\%) and fluid levels localized to the caecum (1.33\%).

For Analysis of Modified Alvarado scores first patients were divided into males, females and children. Out of 150 cases studied 82 are male, 53 are female, and 15 are children (< $12 \mathrm{yrs})$. Out of 75 males Alvarado scores of more than 7 was found in 69 patients while scores of 5-6 and less than 5 were seen in 12 and 1 patients respectively. Out of 60 females Alvarado scores of more than 7 was found in 52 patients while scores of 5-6 and less than 5 were seen in 7 and 1 patients respectively. Out of 15 children patients, score > 7-9 were 12 , score $5-6$ were 2 , score of $<5$ were 1 . These 3 patients of score $<5$ did not undergo surgery.

The diagnosis made on the basis of Modified Alvarado score showed that in patients having Alvarado score more than 7 the sensitivity of diagnosis was very high. In males patients having score of $>7-9,60$ patients had acute appendicitis, 1 patient had normal appendix. In female patients having score of >7-9, 50 patients had acute appendicitis, 1 patient had normal appendix. In children patients having score of $>7-$ 9, 11 patients had acute appendicitis, 1 patient had normal appendix.

In males, females and children the sensitivity of Modified Alvarado score for the diagnosis of acute appendicitis was $84.50 \%, 89.28 \%$ and $84.61 \%$ respectively. As compared to sensitivity, specificity of Alvarado score was found to be less and in males. In females specificity was found to be $50 \%$ and $33.33 \%$ respectively.

Alvarado score of 5-6 was found in 21 patients out of which 12 were males 7 were females and 2 were children. Out of this appendicitis was found in 11, 6 and 2 males. Females and children respectively. 1 male and 1 female with Alvarado score of 5-6 was not found to have appendicitis (table-3). 3 patients with Alvarado scores less than 5 were not operated. The analysis of postoperative complications seen in operated cases showed that out of 147 the most common complication was found to be wound infection (12.22\%) followed by paralytic ileus (11.18\%), diarrhea $(7.11 \%)$ and respiratory tract infection (5.08\%) (table-4).

Finally the histopathological reports of operated appendix (147) were analyzed and most common pathology was found to be Acute Catarrhal (43.24\%) followed by Acute suppurative appendicitis (39.18\%). Gangrenous and perforated appendix were found in $8.10 \%$ and $7.09 \%$ respectively.

\section{DISCUSSION}

Acute appendicitis remains a common abdominal emergency throughout the world. Though in many cases appendicitis can be clinically diagnosed and confirmed on the basis of imaging such as ultrasonography, computerized tomography and Magnetic resonance imaging there are some cases in which clinical examination as well as imaging can't diagnose appendicitis with 100\% accuracy and in these cases there are always chances of appendix turning out to be normal at the time of appendectomy. ${ }^{12}$ Moreover ultrasonography is operator dependent investigation, computerized tomography involves exposure to radiation and magnetic resonance imaging is expensive and not available at many places. In this situation the risk of not operating versus a negative appendectomy exists. ${ }^{13}$

Alvarado A conducted a retrospective study of 305 patients hospitalized with abdominal pain suggestive of acute appendicitis. Signs, symptoms, and laboratory findings were analyzed for specificity, sensitivity, predictive value, and joint probability. ${ }^{10}$ The total joint probability, the sum of a truepositive and a true-negative result, was chosen as a diagnostic weight indicative of the accuracy of the test. Eight predictive factors were found to be useful in making the diagnosis of acute appendicitis. Their importance, according to their diagnostic weight, was determined as follows: localized tenderness in the right lower quadrant, leukocytosis, migration of pain, shift to the left, temperature elevation, nausea-vomiting, anorexia-acetone, and direct rebound pain. Based on this weight the author devised a practical diagnostic score that was helpful in interpreting the confusing picture of acute appendicitis. Later in 1994 M Kalan et al slightly modified Alvarado score by removing one laboratory finding ie shift to the left of neutrophil maturation. ${ }^{11}$ The authors found that this modified Alvarado score also had a high sensitivity, specificity and positive predictive value. Later a larger study by Owen et al involving 215 patients also found similar conclusion. ${ }^{14}$

In our study there were 90 males and 60 females with a M: $\mathrm{F}$ ratio of 1.5:1. The male predominance has been reported by many authors. OOi $\mathrm{BC}$ et $\mathrm{al}^{15}$ conducted a retrospective study of 132 patients in whom Appendectomy was done for Acute Appendicitis. The histological confirmation could be done in 106 patients (80.3\%) and a "negative appendix" rate of $19.7 \%$. The appendix was perforated in 31 patients (23.5\%). In those patients with confirmed Acute Appendicitis, males were predominant (1.7 males: 1 female). Similar male predominance was also reported by Elangovan $\mathrm{S}$ et $\mathrm{al}^{16}$ and Nshuti R et al. ${ }^{17}$

In this study most common age group of the affected patients was found to be between 21-30 years followed by 11-20 years. Similar conclusions were reported by Addiss $\mathrm{DG}^{18}$ who reported that out of approximately 250,000 cases of appendicitis which occur annually in the United the highest incidence of primary positive appendectomy (appendicitis) was found in persons aged 10-19 years (23.3 per 10,000 population per year); males had higher rates of appendicitis than females for all age groups (overall rate ratio, 1.4:1). Similarly Rosser SB et al also reported that appendicitis is more common in adolescent and young adults. ${ }^{19}$

In our study it was found that in males, females and children the sensitivity of Alvarado score for the diagnosis of acute appendicitis was $84.50 \%, 89.28 \%$ and $84.61 \%$ respectively. As compared to sensitivity, specificity of Alvarado score was found to be less and in males, in females specificity was found to be 50\% and 33.33\% respectively. Similarly In 2011 a prospective study was conducted by Kanumba E S et al conducted a study of 127 patients with an aim to evaluate the diagnostic value of Modified Alvarado Scoring System in patients with acute appendicitis. The authors found the sensitivity and specificity of modified Alvarado score in this 
study to b $94.1 \%$ (males $95.8 \%$ and females $88.3 \%$ ) and $90.4 \%$ (males $92.9 \%$ and females $89.7 \%$ ) respectively. The Positive Predictive Value and Negative Predictive Value were $95.2 \%$ (males $95.5 \%$ and females $90.6 \%$ ) and $88.4 \%$ (males $89.3 \%$ and females $80.1 \%$ ) respectively. The accuracy of modified Alvarado score was $92.9 \%$ (males $91.5 \%$ and females $87.6 \%$ ). To conclude most of the findings of our study was similar to the studies in the recent literatures.

\section{CONCLUSION}

Modified Alvarado Score is an effective tool for the diagnosis of acute appendicitis especially in children and men and if used properly may reduce the chances of negative laparotomies considerably. It can be used as a reliable adjunct to surgical decision making in questionable appendicitis.

\section{REFERENCES}

1. Macaluso CR, McNamara RM. Evaluation and management of acute abdominal pain in the emergency department. International Journal of General Medicine. 2012;5(1):789-797.

2. Jones MW, Deppen JG. Appendicitis. [Updated 2018 Mar 20]. In: StatPearls [Internet]. Treasure Island (FL): StatPearls Publishing; 2018 Jan.

3. Keyes el. deaths from appendicitis: the mortality from appendicitis and the causes of death following appendicitis. Annals of Surgery. 1934;99(1):47-68.

4. Leigh DA, Simmons K, Norman E. Bacterial flora of the appendix fossa in appendicitis and postoperative wound infection. Journal of Clinical Pathology. 1974;27(12):997-1000.

5. Choi JY, Ryoo E, Jo JH, Hann T, Kim SM. Risk factors of delayed diagnosis of acute appendicitis in children: for early detection of acute appendicitis. Korean Journal of Pediatrics. 2016;59(9):368-373.

6. Hussain S, Rahman A, Abbasi T, Aziz T. Diagnostic accuracy of ultrasonography in acute appendicitis. J Ayub Med Coll Abbottabad. 2014;26(1):12-7.

7. Sohn M, Agha A, Bremer S, Lehmann KS, Bormann M, Hochrein A. Surgical management of acute appendicitis in adults: A review of current techniques. Int J Surg. 2017;48 (3):232-239.

8. Guida E, Pederiva F, Grazia MD, et al. Perforated appendix with abscess: Immediate or interval appendectomy? Some examples to explain our choice. International Journal of Surgery Case Reports. 2015;12 (5):15-18.

9. Pelde AG, Ruys GJ, Steffelaar JW, Bakker NC. [Fatal course of acute appendicitis associated with infectious mononucleosis]. Ned Tijdschr Geneeskd. 1992;136(30):1471-3.

10. Alvarado A. A practical score for the early diagnosis of acute appendicitis. Ann Emerg Med. 1986;15(5):557564.

11. Kalan M, Talbot D, Cunliffe WJ, Rich AJ. Evaluation of the modified Alvarado score in the diagnosis of acute appendicitis: a prospective study. Annals of The Royal College of Surgeons of England. 1994;76(6):418-419.

12. Seetahal SA, Bolorunduro OB, Sookdeo TC, Oyetunji TA, Greene WR, Frederick W, Cornwell EE 3rd, Chang DC, Siram SM. Negative appendectomy: a 10- year review of a nationally representative sample. Am J Surg. 2011;201(4):433-7

13. Mariadason J,Wang W,Wallack M, Belmonte A, Matari H. Negative appendicectomy rate as a quality metric in the management of appendicitis: impact of computed tomography, Alvarado score and the definition of negative appendicectomy. Annals of The Royal College of Surgeons of England. 2012;94(6):395-401.

14. Owen TD, Williams H, Stiff G, Jenkinson LR, Rees BI. Evaluation of the Alvarado score in acute appendicitis. Journal of the Royal Society of Medicine. 1992;85(2):87-88.

15. Ooi BC, Lim KW, Cheng HK, Joseph VT, Heng A. Acute appendicitis in Singapore children--some clinical aspects. J Singapore Paediatr Soc. 1989;31(3-4):133-7.

16. Elangovan S, Knapp DP, Kallail KJ. Incidence of acute appendicitis confirmed by histopathologic diagnosis. Kans Med. 1997;98(2):10-3.

17. Nshuti R, Kruger D, Luvhengo TE. Clinical presentation of acute appendicitis in adults at the Chris Hani Baragwanath academic hospital. International Journal of Emergency Medicine. 2014;7 (5):12.

18. Addiss DG, Shaffer N, Fowler BS, Tauxe RV. The epidemiology of appendicitis and appendectomy in the United States. Am J Epidemiol. 1990;132(5):910-2.

19. Rosser SB, Nazem A. Appendicitis in the Pediatric Age Group. Journal of the National Medical Association. 1988;80(4):401-403.

20. Kanumba ES, Mabula JB, Rambau P, Chalya PL. Modified Alvarado Scoring System as a diagnostic tool for Acute Appendicitis at Bugando Medical Centre, Mwanza, Tanzania. BMC Surgery. 2011;11:4.

Source of Support: Nil; Conflict of Interest: None

Submitted: 06-08-2018; Accepted: 08-09-2018; Published online: 19-09-2018 